\title{
Immersion and invariance based active disturbance rejection control for LCL grid- connected inverter
}

\author{
Shixiang $\mathrm{Ma}^{*}$, Yong Liu and Guifei Shen \\ School of Automation and Electronic Information, Xiangtan University, Xiangtan, China
}

\begin{abstract}
To improve the anti-disturbance ability of LCL grid-connected inverter system, a novel immersion and invariance based on active disturbance rejection control(I\&I-ADRC) scheme is proposed in this paper. First, the target system with stronger anti-disturbance ability is immersed into the ADRC standard model by using the target system mapping method of immersion and invariance control. Then, the disturbance estimated by extended state observer (ESO) is compensated, and the immersion and invariance(I\&I) control law is adopted to design the state error feedback

(SEF) control law, thus I\&I-ADRC is built, which has improved antidisturbance ability and dynamic response performance. The stability of grid-connected inverter system is proved by Lyapunov theory. Simulation results show that the proposed strategy can effectively suppress the disturbance and has better tracking performance.
\end{abstract}

Keywords: LCL filter, Grid-connected inverter, Active disturbance rejection control, Immersion and invariance control, State error feedback.

\section{Introduction}

Grid-connected inverter is the hub connecting distributed generation and public power grid, which plays a key role in the stability of the system. LCL grid-connected inverter is widely applied due to its stronger high frequency suppression ability and smaller volume than the traditional L grid-connected inverter [1]. However, LCL grid-connected inverter is high-order system [2], and the actual operation condition is complex. Inverter becomes an uncertain system that is subject to various kinds of disturbances, such as the harmonic generated in the modulation process of inverter and grid voltage disturbances. At present, how to improve the anti-disturbance ability and robustness of the control strategy has become a research hotspot of LCL inverter.

With the development of control theory, a variety of control strategies with strong antidisturbance ability have appeared and widely employed in LCL inverter, such as sliding mode control, robust control, model predictive control, adaptive control and disturbance observer [3-8]. Active disturbance rejection control (ADRC) is a kind of control strategy

\footnotetext{
*Corresponding author: 201821562025@smail.xtu.edu.cn
} 
which does not require an accurate mathematical model of the control target [9], which has strong robustness and anti-disturbance ability. the extended state observer (ESO) can not only estimate the state of the system, but also estimate the real-time effects of internal disturbances caused by model uncertainty and environment-induced external disturbances and compensate for them, the system is transformed into an integral series structure by compensation, and then the feedback control law is applied. Finally, the system can obtain good anti-disturbance ability and dynamic response ability. To solve the problems of complex calculation and difficult parameter tuning of ADRC, the linear active disturbance rejection control (LADRC) was proposed [10], which simplified many parameters into observation bandwidth and control bandwidth, making the tuning of control parameters easier.

Based on the third-order LADRC, the derivative observation signal obtained from the linear extended state observer (LESO) is used as the active damping feedback to suppress the resonance in LCL inverter system [11]. A direct pole placement controller is designed by ESO, which has good performance in suppressing external disturbances, internal coupling and parameter variations [12]. In [13] and [14], the time-varying gain observer is designed to ensure the convergence of observation error and effectively suppress the initial derivative peaking phenomenon of constant gain ESO, it has improved the observation accuracy. In [15], the third-order LCL model is reduced to the second-order model by using the concept of relative order, and the second-order LADRC is designed to realize decoupling control of grid-connected current. In [16], the third-order LCL inverter model is reduced to the first-order model by padé approximation, and the grid-connected current is controlled by the first-order LADRC. The existing literatures are from the level of ESO and system order to improve the anti-disturbance ability of the system, there are few literatures on the control law.

The paper proposes a novel immersion and invariance based active disturbance rejection control (I\&I-ADRC) for LCL grid-connected inverter to improve the anti-disturbance ability. Its essence is to improve the traditional ADRC control law, the target system with sliding mode approach law is immersed into ADRC standard model by using the mapping method of immersion and invariance control, which enhances the anti-disturbance ability of the closed-loop system. The I\&I-ADRC combines an immersion and invariance control law with a LESO, which obtains high anti-disturbance ability and better dynamic response performance. the stability of LCL grid-connected inverter with the proposed controller is proved by using the Lyapunov theory. The proposed strategy is applied to the current control of grid-connected inverter and verified by simulation. The results show that compared with the traditional LADRC, the proposed strategy has better interference suppression ability and tracking performance.

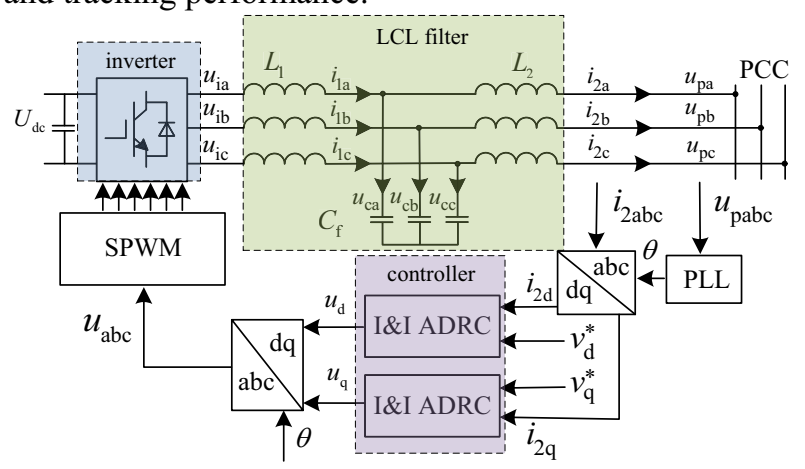

Fig.1. Block diagram of the LCL grid-connected inverter controlled by the ADRC strategy. 


\section{LCL model based on ADRC strategy}

Figure 1 depicts a block diagram of the LCL grid-connected inverter controlled by the ADRC strategy. $\theta$ is the phase of the grid voltage obtained by the phase locked loop (PLL) here it is assumed that the PLL is always accurate. $v_{\mathrm{d}}^{*}$ and $v_{\mathrm{q}}^{*}$ are reference values of gridconnected current of d-q axis; $u_{\mathrm{d}}$ and $u_{\mathrm{q}}$ are the output signals of the d-q axis controller.

Combined with Figure 1, the third-order dynamic equation of grid-connected current $\mathrm{i}_{2 \mathrm{abc}}$ in $\mathrm{d}-\mathrm{q}$ coordinates can be expressed as [11]

$$
\left\{\begin{array}{l}
\frac{d^{3} i_{2 \mathrm{~d}}}{d t^{3}}=\frac{K_{\mathrm{pwm}}}{L_{1} L_{2} C_{\mathrm{f}}} u_{\mathrm{d}}+w_{\mathrm{d}} \\
\frac{d^{3} i_{2 \mathrm{q}}}{d t^{3}}=\frac{K_{\mathrm{pwm}}}{L_{1} L_{2} C_{\mathrm{f}}} u_{\mathrm{q}}+w_{\mathrm{q}}
\end{array}\right.
$$

where $K_{\mathrm{pwm}}=U_{\mathrm{dc}} / 2$ is the gain of the inverter, and wd and wq are the internal dynamics and other external disturbances of the system, which are called the total disturbance. According to (1) to design ADRC controller, because of the dual relationship between daxis and q-axis equation, only d-axis is analyzed in the following, and q-axis analysis is similar.

\section{Traditional ADRC design}

The active disturbance rejection controller is composed of a tracking differentiator (TD), an extended state observer and a state error feedback (SEF) control law, where TD plays a role in estimating the derivative of the reference signal, considering that the reference signal under the dq coordinate is a direct current Therefore, this structure is omitted.

Expanding $w_{\mathrm{d}}$ in (1) into a new state, the following expanded state space equation can be established

$$
\left\{\begin{array}{l}
\dot{x}_{1}=x_{2} \\
\dot{x}_{2}=x_{3} \\
\dot{x}_{3}=b_{0} u+x_{4} \\
\dot{x}_{4}=h \\
y=x_{1}
\end{array}\right.
$$

where $x_{1}=y, x_{2}=\dot{y}, x_{3}=\ddot{y}, x_{4}=w_{\mathrm{d}}$, and $y=i_{2 \mathrm{~d}}$ is the output of the system. $b_{0}=K_{\mathrm{pwm}} /\left(L_{1} L_{2} C_{\mathrm{f}}\right)$ is the input gain, and $h=\dot{w}_{\mathrm{d}}$ is the derivative of the unknown disturbance.

For (2), a linear extended state observer is established 


$$
\left\{\begin{array}{l}
\dot{\hat{x}}_{1}=\hat{x}_{2}-\beta_{1}(\hat{y}-y) \\
\dot{\hat{x}}_{2}=\hat{x}_{3}-\beta_{2}(\hat{y}-y) \\
\dot{\hat{x}}_{3}=b_{0} u+f_{0}+\hat{x}_{4}-\beta_{3}(\hat{y}-y) \\
\dot{\hat{x}}_{4}=-\beta_{4}(\hat{y}-y)
\end{array}\right.
$$

where $\beta_{\mathrm{j}}>0(j=1,2,3,4)$ is the error feedback gain of the extended observer. According to [10], the value of $\beta_{\mathrm{j}}$ can be selected as

$$
\beta_{1}=4 \omega_{\mathrm{o}}, \beta_{2}=6 \omega_{\mathrm{o}}^{2}, \beta_{3}=4 \omega_{\mathrm{o}}^{3}, \beta_{4}=\omega_{\mathrm{o}}^{4},
$$

where $\omega_{\mathrm{o}}$ is the observation bandwidth and the value of $\omega_{\mathrm{o}}$ can be adjusted appropriately

$$
\hat{x}_{1} \rightarrow x_{1}, \hat{x}_{2} \rightarrow x_{2}, \hat{x}_{3} \rightarrow x_{3}, \hat{x}_{4} \rightarrow x_{4}
$$

At this time, the feedforward compensation can be set as

$$
u=\frac{u_{0}-f_{0}-\hat{x}_{4}}{b_{0}}
$$

Substitute (6) into (2)

$$
\left\{\begin{array}{l}
\dot{x}_{1}=x_{2} \\
\dot{x}_{2}=x_{3} \\
\dot{x}_{3}=u_{0}+x_{4}-\hat{x}_{4} \approx u_{0} \\
y=x_{1}
\end{array}\right.
$$

When $\hat{x}_{4}$ estimates the total disturbance in the system accurately, the system (7) can be regarded as a pure integral series object. At this time, there is no disturbance in the system, so the control of the system can be realized by designing SEF with proportional-differential structure for $u_{0}$ [17]. When a strong disturbance occurs in the system, the traditional SEF has insufficient anti-disturbance ability. Therefore, in order to enhance the anti-disturbance performance, a method of using the immersion and invariance control law to replace the traditional SEF is proposed.

\section{I\&I-ADRC Controller}

\subsection{Basic Principles of $|\&|$}

Its main conclusion can be summarized as Theorem 1 [18].

Theorem 1: Consider the following nonlinear systems:

$$
\dot{X}=f(X)+g(X) u
$$


Among them, $X \in R^{n}$ is the state variable, $u \in R^{m}$ is the control input, and the equilibrium point $X^{*} \in R^{n}$ is stable. Let $\mathrm{p}<\mathrm{n}$ and assume there is a mapping

$$
\left\{\begin{array}{c}
\alpha: R^{p} \rightarrow R^{p}, \Gamma: R^{p} \rightarrow R^{n}, c: R^{p} \rightarrow R^{m} \\
\Phi: R^{n} \rightarrow R^{n-p}, \Psi: R^{n \times(n-p)} \rightarrow R^{m}
\end{array}\right.
$$

So that the following conditions are true:

H1) Target dynamic system

$$
\dot{\xi}=\alpha(\xi)
$$

Among them, $\xi \in R^{\mathrm{p}}$ is the target dynamic state quantity, and the equilibrium points $\xi^{*} \in R^{\mathrm{p}}$ and $X^{*}=\Gamma\left(\xi^{*}\right)$ are asymptotically stable.

Immersion conditions. For all $\xi \in R^{\mathrm{p}}$

$$
f(\Gamma(\xi))+g(\Gamma(\xi)) c(\Gamma(\xi))=\frac{\partial \Gamma}{\partial \xi} \alpha(\xi)
$$

Implicit manifold. The following equation always holds

$$
\left\{X \in R^{\mathrm{n}} \mid \Phi(X)=0\right\}=\left\{X \in R^{\mathrm{n}} \mid X=\Gamma(\xi) \text {, 对于一些 } \xi \in R^{\mathrm{p}}\right\}
$$

Manifold attractivity and trajectory boundedness. When the following formula holds:

$$
\lim _{t \rightarrow \infty} z(t) \rightarrow 0
$$

The following system

$$
\begin{gathered}
\dot{z}=\frac{\partial \Phi}{\partial X}[f(X)+g(X) \Psi(X, z)] \\
f(X)+g(X) \Psi(X, z)
\end{gathered}
$$

All trajectories are bounded. Then $X^{*}$ is the asymptotically stable equilibrium point of the following closed-loop system

$$
\dot{X}=f(X)+g(X) \Phi(X, z)
$$

The corresponding control law $u=\Phi(X, z)$ can make the offline coordinate $\mathrm{z}$ converge to zero and the system trajectory is bounded.

\subsection{Immersion and Invariance control law}

Immersion and invariance can map the low-level target system to the high-level system, so that the entire system has the same response characteristics as the target system. Therefore, the target system with stronger anti-disturbance performance can be selected and mapped to 
the system (7), so that the immersion and invariance control law can be designed to enhance the anti-disturbance ability of the active disturbance rejection controller.

The immersion target system of the designated system (7) is

$$
\dot{\xi}=\alpha(\xi)
$$

Assume that the system has the only equilibrium point that meets the $\mathrm{H} 1$ condition.

Then select a suitable mapping $\Gamma(\xi)$ to satisfy the $\mathrm{H} 2$ condition

$$
\left\{\begin{array}{l}
\Gamma_{1}(\xi)=\xi \\
\Gamma_{2}(\xi)=\alpha(\xi) \\
\Gamma_{3}(\xi)=\frac{\partial \alpha}{\partial \xi} \alpha(\xi)
\end{array}\right.
$$

Then the following equation holds

$$
\left\{\begin{array}{l}
\Gamma_{2}(\xi)=\frac{\partial \Gamma_{1}}{\partial \xi} \alpha(\xi) \\
\Gamma_{3}(\xi)=\frac{\partial \Gamma_{2}}{\partial \xi} \alpha(\xi) \\
c(\Gamma(\xi))=\frac{\partial \Gamma_{3}}{\partial \xi} \alpha(\xi)
\end{array}\right.
$$

To ensure condition $\mathrm{H} 3$, select the following function

$$
\left\{\begin{array}{l}
\Phi_{1}=x_{2}-\alpha\left(x_{1}\right) \\
\Phi_{2}=x_{3}-\alpha^{\prime}\left(x_{1}\right) x_{2}+k_{z}\left(x_{2}-\alpha\left(x_{1}\right)\right)
\end{array}\right.
$$

It is easy to know that when the following relationship is satisfied

$$
\left\{\begin{array}{l}
x_{1}=\Gamma_{1}(\xi) \\
x_{2}=\Gamma_{2}(\xi) \\
x_{3}=\Gamma_{3}(\xi)
\end{array}\right.
$$

There is $\Phi_{1}=0, \Phi_{2}=0$, and the $\mathrm{H} 3$ condition is satisfied. Define the following equation

$$
\left\{\begin{array}{l}
z_{1}=x_{2}-\alpha\left(x_{1}\right) \\
z_{2}=x_{3}-\alpha^{\prime}\left(x_{1}\right) x_{2}+k_{z}\left(x_{2}-\alpha\left(x_{1}\right)\right)
\end{array}\right.
$$

Deriving it

$$
\left\{\begin{array}{c}
\dot{z}_{1}=x_{3}-\alpha^{\prime}\left(x_{1}\right) x_{2}=z_{2}-k_{z} z_{1} \\
\dot{z}_{2}=u_{0}-\alpha^{\prime \prime}\left(x_{1}\right) x_{2}^{2}-\alpha^{\prime}\left(x_{1}\right) x_{3}+k_{z}\left(x_{3}-\alpha^{\prime}\left(x_{1}\right) x_{2}\right)
\end{array}\right.
$$


Define the following equation

$$
u_{0}=-k_{\mathrm{z}} z_{2}+\alpha^{\prime \prime}\left(x_{1}\right) x_{2}^{2}+\alpha^{\prime}\left(x_{1}\right) x_{3}-k_{\mathrm{z}}\left(x_{3}-\alpha^{\prime}\left(x_{1}\right) x_{2}\right)
$$

Therefore, the following relationship is established

$$
\left\{\begin{array}{l}
\dot{z}_{1}=z_{2}-k_{\mathrm{z}} z_{1} \\
\dot{z}_{2}=-k_{\mathrm{z}} z_{2}
\end{array}\right.
$$

It is easy to know that when parameter $k_{\mathrm{z}}>0$, all states of the system (25) are bounded and asymptotically stable, that is, there is

$$
\lim _{t \rightarrow \infty} z_{1}(t) \rightarrow 0, \lim _{t \rightarrow \infty} z_{2}(t) \rightarrow 0
$$

Condition $\mathrm{H} 4$ is satisfied. At this point, the above satisfies all the conditions of immersion and invariance $\mathrm{H} 1$ to $\mathrm{H} 4$, so the equilibrium point $X^{*}$ of the original system (7) converges asymptotically and the trajectory is bounded.

In immersion and invariance control, the target system determines the response performance of the closed-loop system. Therefore, in order to improve the overall antidisturbance ability, it is necessary to select the target system with strong anti- disturbance ability. Due to the excellent disturbance rejection ability of sliding mode control, the target system can be set as a system with sliding mode control law. Referring to the constant velocity reaching law $\dot{s}=-k_{s} \operatorname{sgn}(s)$, in order to ensure the smoothness of the function, the sign function is replaced by the smooth saturation function, and the hyperbolic tangent function meets this requirement. Since the reference signal is a DC signal, only the case that the reference value $\mathrm{f}$ is a constant is considered.

Finally, the feedback function of the target system can be set to

$$
\alpha(\xi)=-k_{\mathrm{z}} \tanh \left(\frac{\xi-v_{0}}{\delta}\right)
$$

where $\delta>0$, and with $\delta \rightarrow 0$, the function tanh gradually approximates the signed function sgn.

Substitute (22) for (24)

$$
\begin{aligned}
& u_{0}=-k_{\mathrm{z}}\left(x_{3}-\alpha^{\prime}\left(x_{1}\right) x_{2}+k_{z}\left(x_{2}-\alpha\left(x_{1}\right)\right)\right)+\alpha^{\prime \prime}\left(x_{1}\right) x_{2}^{2}+\alpha^{\prime}\left(x_{1}\right) x_{3}-k_{\mathrm{z}}\left(x_{3}-\alpha^{\prime}\left(x_{1}\right) x_{2}\right) \\
& =-2 k_{\mathrm{z}} x_{3}-k_{\mathrm{z}}^{2} x_{2}+k_{\mathrm{z}}^{2} \alpha\left(x_{1}\right)+\alpha^{\prime}\left(x_{1}\right) x_{3}+2 k_{\mathrm{z}} \alpha^{\prime}\left(x_{1}\right) x_{2}+\alpha^{\prime \prime}\left(x_{1}\right) x_{2}^{2}
\end{aligned}
$$

Since the state variables $x_{2}$ and $x_{3}$ of the above formula can not be obtained directly, the estimated values $\hat{x}_{2}$ and $\hat{x}_{3}$ of the extended state observer (3) are used instead. The actual immersion and invariance control laws are obtained as follows

$$
u_{0}=-2 k_{\mathrm{z}} \hat{x}_{3}-k_{\mathrm{z}}^{2} \hat{x}_{2}+k_{\mathrm{z}}^{2} \alpha\left(x_{1}\right)+\alpha^{\prime}\left(x_{1}\right) \hat{x}_{3}+2 k_{\mathrm{z}} \alpha^{\prime}\left(x_{1}\right) \hat{x}_{2}+\alpha^{\prime \prime}\left(x_{1}\right) \hat{x}_{2}^{2}
$$

Then the overall structure of the I\&I-ADRC is as follows 


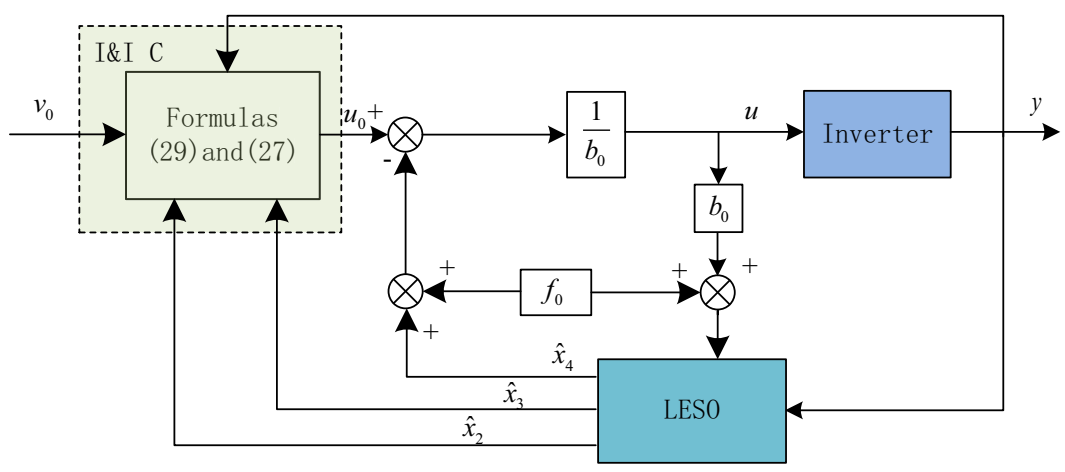

Fig. 2. I\&I-ADRC controller structure.

\section{Proof of stability}

Theorem 2: For system (2), construct LESO with expression (3), feed forward compensation (6), and satisfy the relationship of (4), then adopt the immersion and invariant control law (29) to make the closed-loop system stable.

Proof: select the lyapunov function as

$$
V=\frac{1}{2} z_{1}^{2}+\frac{1}{2} z_{2}^{2}
$$

Combining (22), (7) and (29) to obtain the derivative

$$
\begin{aligned}
& \dot{V}=z_{1} \dot{z}_{1}+z_{2} \dot{z}_{2} \\
& =z_{1}\left(z_{2}-k_{\mathrm{z}} z_{1}\right)+z_{2}\left[u_{0}-\alpha^{\prime \prime}\left(x_{1}\right) x_{2}^{2}-\alpha^{\prime}\left(x_{1}\right) x_{3}+k_{\mathrm{z}}\left(x_{3}-\alpha^{\prime}\left(x_{1}\right) x_{2}\right)+\hat{x}_{4}-x_{4}\right] \\
& =z_{1}\left(z_{2}-k_{\mathrm{z}} z_{1}\right)+z_{2}\left(-k_{\mathrm{z}} z_{2}+\varpi\right)
\end{aligned}
$$

where

$$
\varpi=-2 k_{\mathrm{z}} \tilde{x}_{3}-k_{\mathrm{z}}^{2} \tilde{x}_{2}+k_{\mathrm{z}}^{2} \alpha\left(x_{1}\right)+\alpha^{\prime}\left(x_{1}\right) \tilde{x}_{3}+2 k_{\mathrm{z}} \alpha^{\prime}\left(x_{1}\right) \tilde{x}_{2}+\alpha^{\prime \prime}\left(x_{1}\right)\left(\hat{x}_{2}^{2}-x_{2}^{2}\right)+\hat{x}_{4}-x_{4}
$$

And $\tilde{x}_{3}=\hat{x}_{3}-x_{3}, \tilde{x}_{2}=\hat{x}_{2}-x_{2}$, according to (27), it is easy to know that function $\alpha$ and its first derivative $\alpha^{\prime}$ and second derivative $\alpha^{\prime \prime}$ are all bounded functions, and since [19] proves that the estimation error of LESO is bounded, it can be obtained

$$
|\varpi| \leq M<\infty
$$

There are

$$
\dot{V} \leq-k_{\mathrm{z}} z_{1}^{2}-k_{\mathrm{z}} z_{2}^{2}+\frac{1}{2} z_{1}^{2}+\frac{1}{2} z_{2}^{2}+\frac{1}{2} z_{2}^{2}+\frac{1}{2} \varpi^{2} \leq-\left(2 k_{\mathrm{z}}-1\right) V+\frac{1}{2} M^{2}
$$

By multiplying both sides of the above formula by $e^{-\left(2 k_{\mathrm{z}}-1\right) t}$ and seeking definite integral 


$$
V \leq \frac{M^{2}}{2\left(2 k_{\mathrm{z}}-1\right)}+\left[V(0)-\frac{M^{2}}{2\left(k_{\mathrm{z}}-1\right)}\right] e^{-\left(2 k_{\mathrm{z}}-1\right) t}
$$

There are

$$
\begin{gathered}
\lim _{t \rightarrow \infty}\left|z_{1}\right| \leq \lim _{t \rightarrow \infty} \sqrt{2 V(t)} \leq \sqrt{\frac{M^{2}}{\left(2 k_{\mathrm{z}}-1\right)}}=\varsigma_{\mathrm{z}} \\
\lim _{t \rightarrow \infty}\left|z_{2}\right| \leq \lim _{t \rightarrow \infty} \sqrt{2 V(t)} \leq \sqrt{\frac{M^{2}}{\left(2 k_{\mathrm{z}}-1\right)}}=\varsigma_{\mathrm{z}}
\end{gathered}
$$

Defining $e_{1}=x_{1}-v_{0}$, we can combine (22) and (2) to obtain the following equation

$$
\dot{e}_{1}=-k_{\mathrm{z}} \tanh \frac{e_{1}}{\delta}+z_{1}
$$

According to (36), $z_{1}$ is a bounded signal, so it can be regarded as the external disturbance of the system (38). Since (38) is designed according to the sliding mode reaching law, it is stable under the influence of bounded disturbance signal $z_{1}$. So far, both $z_{1}$ and $z_{2}$ are bounded and stable, so that the entire closed-loop system is stable.

\section{Simulation}

In order to verify the proposed strategy, the simulation models of the proposed controller and LCL inverter are built on MATLAB/Simulink simulation software. When harmonic voltage and unbalanced voltage exist in the power grid, it is compared with the traditional LADRC control strategy. The inverter parameters are $L_{1}=1.4 \mathrm{mH}, C_{\mathrm{f}}=50 \mu \mathrm{F}$, $L_{2}=1.2 \mathrm{mH}$ and $U_{\mathrm{dc}}=800 \mathrm{~V}$ carrier frequency is $10000 \mathrm{hz}$, and I\&I-ADRC parameters are $k_{z}=6000, \delta=0.1$ and $\omega_{\mathrm{o}}=15000$ The parameter of traditional LADRC are $\omega_{\mathrm{c}}=6000, \omega_{\mathrm{o}}=15000$.

\subsection{Tracking of reference instructions}

To investigate the tracking performance of I\&I-ADRC to reference command current, the simulation settings are as follows: when $0.05 \mathrm{~s}$, the q-axis reference current steps from $0 \mathrm{~A}$ to $20 \mathrm{~A}$; when $0.1 \mathrm{~s}$, the d-axis reference current steps from $25 \mathrm{~A}$ to $15 \mathrm{~A}$. Figure 3 shows the reference and actual d-axis and q-axis currents in I\&I-ADRC, as well as the corresponding three-phase grid-connected current. The test results show that the proposed control strategy has good tracking performance for reference instruction current, strong adaptability for reference instruction mutation, smooth tracking and no overshoot in mutation process, and stable state in less than half cycle of fundamental wave after instruction mutation. The proposed control strategy has good dynamic response ability. 


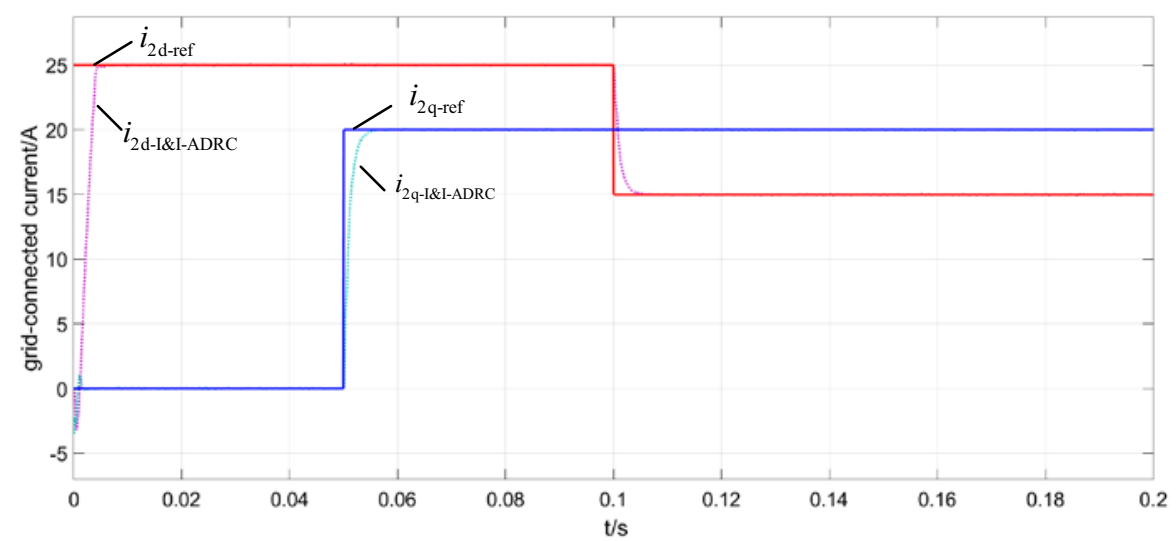

(a)

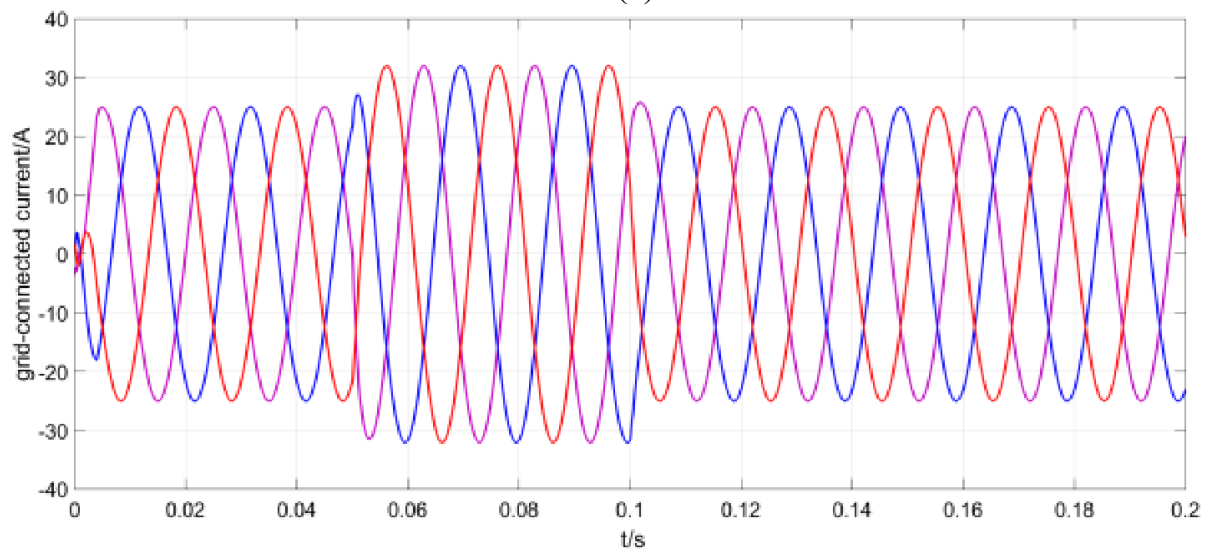

(b)

Fig. 3. Reference current tracking response.

\subsection{Interference suppression}

The LCL inverter system is continuously affected by the grid voltage disturbance. To investigate the disturbance suppression of the proposed strategy, the harmonic and unbalanced grid voltage are tested respectively. The odd harmonic component of fundamental frequency mainly exists in the power grid, so the 5th harmonic with $7 \%$ content and the 7th harmonic with 3\% content are injected into the power grid in the test. It can be seen from Figure 4 that after adding harmonics to the grid voltage, the gridconnected current is also distorted due to the influence of grid voltage. The grid-connected current controlled by traditional LADRC in Figure 4 (a) is obviously distorted, and the harmonic distortion rate (THD) in Figure 4 (c) is $1.39 \%$. However, the grid-connected current controlled by I\&I-ADRC in Figure 4 (b) has almost no distortion, and Figure 4 (d) shows that its THD is only $0.39 \%$. This shows that I\&I-ADRC can more effectively suppress grid-connected current distortion caused by harmonic disturbance. 


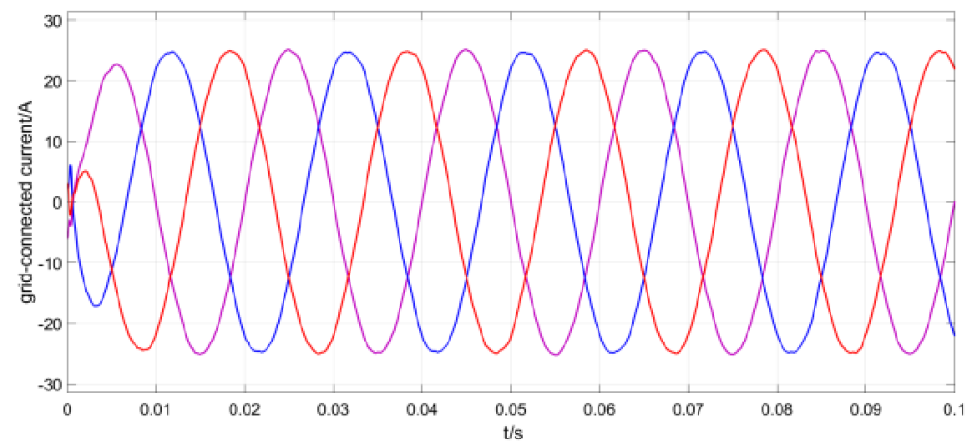

(a)

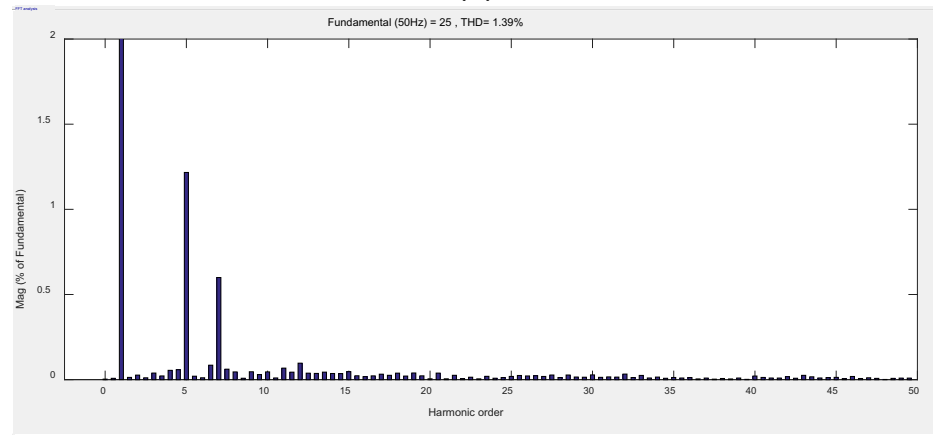

(c)

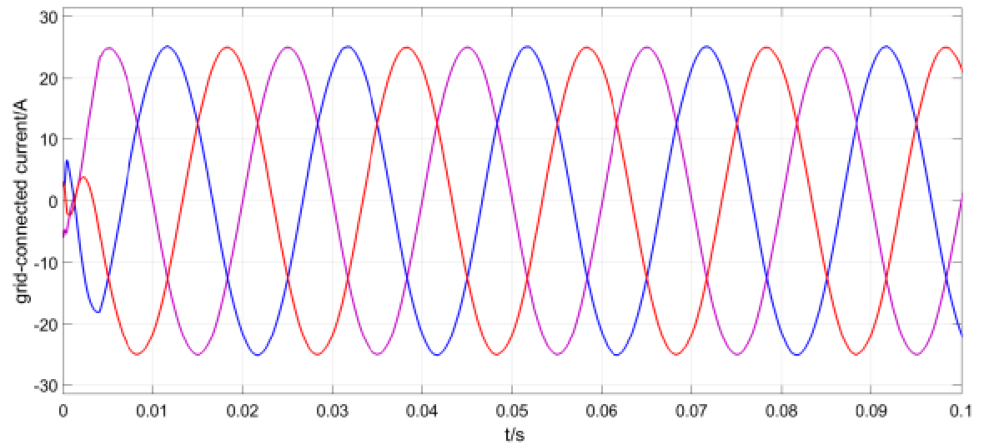

(b)

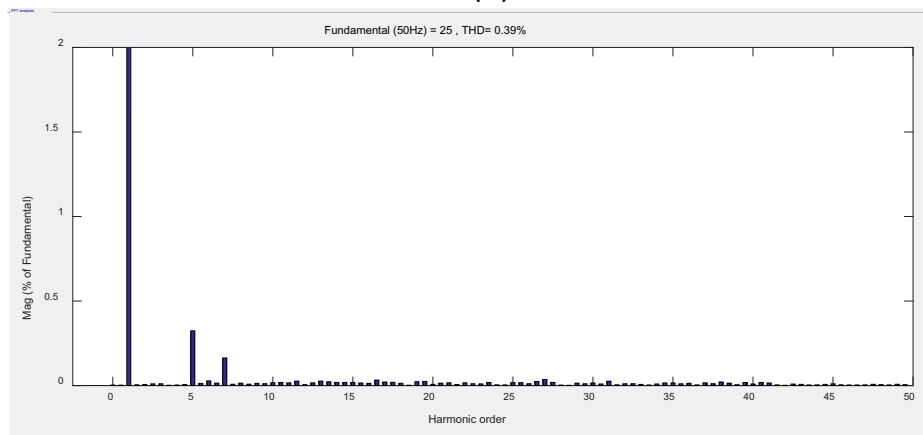

(d)

Fig. 4. Comparison of grid-connected current under the control of traditional LADRC and I\&I-ADRC when the power grid contains harmonics. 
The negative sequence voltage of $15 \%$ is injected into the grid voltage, the suppression ability of the two strategies to grid voltage imbalance is compared by analyzing the imbalance degree of grid-connected current, as shown in Figure 5. when the grid voltage is unbalanced, the grid-connected current controlled by the traditional LADRC strategy is obviously unbalanced. Through calculation, the unbalance degree of grid-connected current under traditional LADRC control is $2.30 \%$, while the unbalance degree of grid-connected current under I\&I-ADRC control is only $0.57 \%$. Injecting different degrees of negative sequence voltage into the power grid will increases the voltage imbalance of the power grid. Figure 6 shows the line chart of unbalanced comparison of grid-connected current controlled by the two strategies under different voltage imbalance conditions. The gridconnected current under the proposed I\&I-ADRC strategy keeps a low degree of imbalance, while the grid-connected current under the traditional LADRC strategy keeps a high degree of imbalance. This shows that the proposed I\&I-ADRC control strategy has a better suppression effect on the disturbance caused by the grid voltage imbalance.

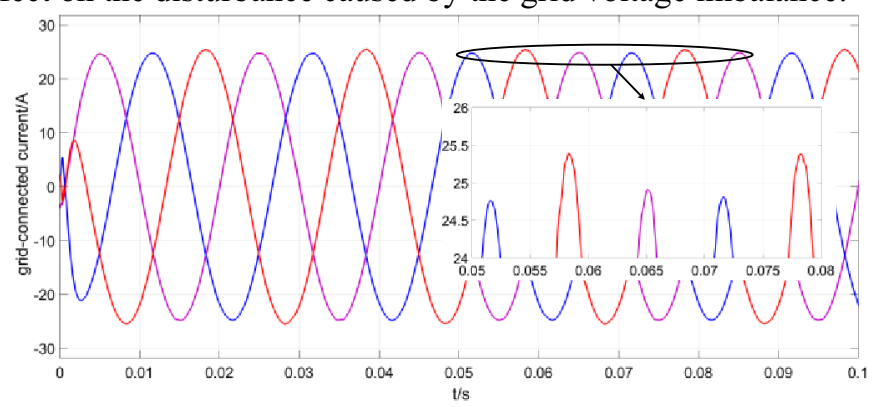

(a)

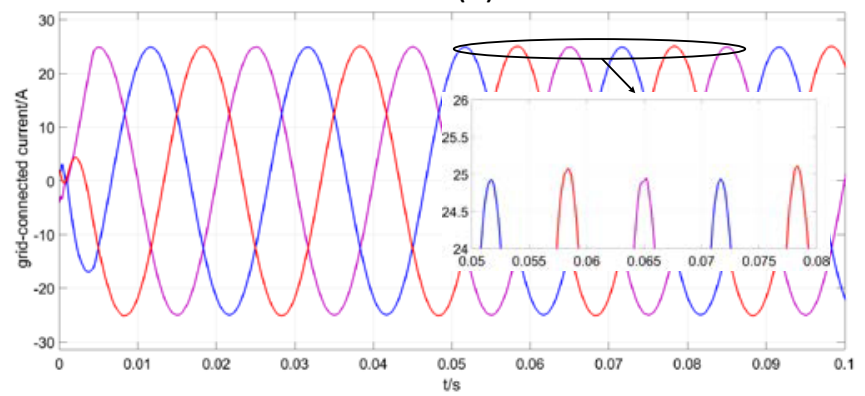

(b)

Fig. 5. Comparison of grid-connected current under the control of traditional LADRC and I\&I-ADRC when the grid is unbalanced.

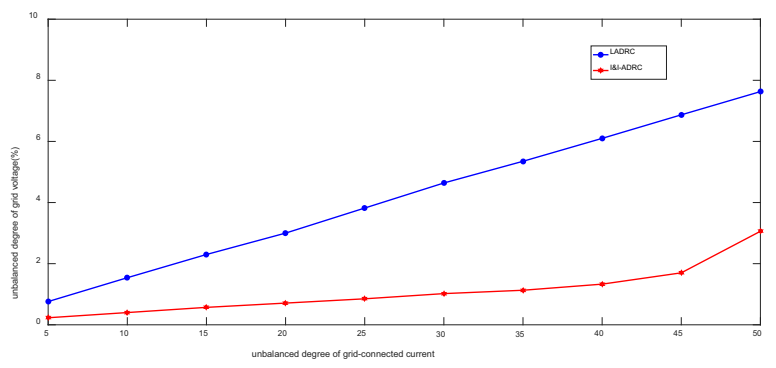

Fig. 6. Comparison of grid-connected current imbalance under different grid voltage imbalance conditions. 


\section{Conclusion}

In this paper, I\&I-ADRC control strategy for LCL inverter is proposed. the I\&I control law is adopted to design the SEF control law in traditional LADRC, finally, I\&I-ADRC is built. The target system with sliding mode reaching law is selected to enhance the antidisturbance ability of the closed-loop system. The stability of the controller is proved by Lyapunov stability theory. The simulation results show that the proposed control strategy has better anti-disturbance performance than the traditional LADRC control strategy when the disturbance changes.

\section{References}

1. ZHOU X, LU S. A Novel Inverter-Side Current Control Method of LCL-Filtered Inverters Based on High-Pass-Filtered Capacitor Voltage Feedforward [J] IEEE Access, 2020, 8:16528-1653.

2. QU K Q, LI W Q, YE T K, et al. State Feedback Based Decoupling Control Strategy for Grid-Connected Inverter with LCL Filter[J]. Transactions of China Electrotechnical Society, 2016, 31(20):130-138.

3. GUZMAN R, VICUÑA L G D, CASTILLA M, et al. Variable Structure Control in Natural Frame for Three-Phase Grid-Connected Inverters With LCL Filter[J]. IEEE Transactions on Power Electronics, 2018, 33(5):4512-4522.

4. ZHENG L, JIANG F, SONG J, et al. A Discrete-Time Repetitive Sliding Mode Control for Voltage Source Inverters[J]. IEEE Journal of Emerging and Selected Topics in Power Electronics, 2018, 6(3):1553-1566.

5. KOCH G G, MACCARI L A, OLIVEIRA R C L F, et al. Robust $H_{\infty}$ State Feedback Controllers Based on Linear Matrix Inequalities Applied to Grid-Connected Converters[J]. IEEE Transactions on Industrial Electronics, 2018, 66(8): 6021-6031.

6. FALKOWSKI P, SIKORSKI A. Finite Control Set Model Predictive Control for GridConnected AC-DC Converters With LCL Filter[J]. IEEE Transactions on Industrial Electronics, 2018, 65(4):2844-2852.

7. MASSING J R, STEFANELlO M, GRUNDLING H A, et al. Adaptive Current Control for Grid-Connected Converters With LCL Filter. IEEE Transactions on Industrial Electronics, 2012, 59(12):4681-4693.

8. AL-DURRA A, ERROUISSI R. Robust Feedback-Linearization Technique for GridTied LCL Filter Systems Using Disturbance Estimation. IEEE Transactions on Industry Applications, 2019, 55(3):3185-3197.

9. HAN J Q.Active Disturbance Rejection Control control technology [M].Beijing:National Defense Industry Press,2008.

10. GAO Z. Scaling and bandwidth-parameterization based controller tuning[C] //Proceedings of the 2003 American Control Conference. Denver, USA:IEEE, 2003:4989-4996.

11. YANG L, ZENG J, HUANG Z. Application of Linear Active Disturbance Rejection Technique in Grid-Connected Current Control and Active Damping of LCL Type Inverter[J]. Power System Technology, 2019, 43(04):1378-1386.

12. LU J, SAVAGHEBI M, GUERRERO J M, et al. Linear active disturbance rejection control for LCL type grid-connected converter[C]//IECON 2016-42nd Annual 
Conference of the IEEE Industrial Electronics Society, Florence, Italy:IEEE, 2016:3458-3463.

13. SUN D S, ZHANG Y J. Improved third-order time-varying parameters nonlinear ESO restraining the derivative peaking phenomenon[J]. Electric Machines and Control,2017,21(09):55-62.

14. TENG Q F, ZUO J, PAN H, et al. Robust voltage control for inverter system using time-varying gain extended state observer-based adaptive super-twisting algorithm[J]. Control Theory \& Applications,2020,37(09):1880-1894.

15. YANG L, ZENG J, HUANG Z L, et al. Current decoupling control of three-phase LCL-type grid-connected inverter based on linear active disturbance rejection technique[J]. Electrical Measurement \& Instrumentation:1-8[2020-07-25]. http://kns.cnki.net/kcms/detail/23.1202.TH.20181208.0956.012.html.

16. BENRABAH A, XU D, GAO Z. Active Disturbance Rejection Control of LCLFiltered Grid-Connected Inverter Using Padé Approximation[J]. IEEE Transactions on Industry Applications, 2018, 54(6):6179-6189.

17. WANG C Y, PENG Y G, SHI H W, etal. Design of al inear disturbance rejection controller for photoelectric stabilized platform[J]. Electronics Optics \& Control, 2018, 25(11):112-115, 119.

18. LI XJ, WU A G, ZHANG Z L. Immersion and invariance modular nonlinear tracking control for an underactuated quadrotor[J]. Control Theory \& Applications,2019,36(01):73-78.

19. CHEN Z Q, SUN M M, YANG R G. On the Stability of Linear Active Disturbance Rejection Control[J]. Acta Automatica Sinica, 2013, 39(05):574-580. 